Role of Expatriate Adjustment 1

\title{
Antecedents and consequences of the perceived adjustment of Japanese
}

expatriates in the USA

\author{
Riki Takeuchi \\ 3354 Van Munching Hall \\ Robert H. Smith School of Business \\ University of Maryland \\ College Park, MD 20742 \\ Voice: (301) 403-2746 \\ Fax: (301) 314-8787 \\ E-mail: rtakeuch@rhsmith.umd.edu \\ Seokhwa Yun \\ Partridge Hall \#338 \\ Department of Management \\ School of Business \\ Montclair State University \\ Upper Montclair, New Jersey 07043 \\ Voice: (973) 655-7230 \\ Fax: (973) 655-4456 \\ E-mail:yuns@mail.montclair.edu \\ Joyce E. A. Russell \\ 3347 Van Munching Hall \\ Robert H. Smith School of Business \\ University of Maryland \\ College Park, MD 20742 \\ Voice: (301) 405-8145 \\ Fax: (301) 314-8787 \\ E-mail: jrussell@rhsmith.umd.edu
}

International Journal of Human Resource Management, 2002

\section{Acknowledgement}

We acknowledge the tremendous assistance provided by John M. Hannon, Kazuo

Takeuchi, and Keiko Takeuchi throughout the data collection process. We also

greatly appreciate the insightful comments provided by M. Susan Taylor and

David P. Lepak. 


\title{
Antecedents and consequences of the perceived adjustment of Japanese expatriates in the USA
}

\begin{abstract}
The present study was designed to better understand the antecedents and consequences of expatriate adjustment in an international assignment. The researchers surveyed Japanese expatriates assigned to the United States. Structural equation modeling was utilized to test our hypotheses and model. The results indicated that previous knowledge of the host country, language proficiency, willingness to communicate, and perception of the novelty of the host culture were differentially related to expatriates' adjustment to the host country. General and work adjustments were negatively related to expatriates’ intent to return early. In addition, interrelationships among the adjustment dimensions were examined and the results indicated that general adjustment leads to work adjustment, which, in turn, influences interactional adjustment. Implications for future research are presented.
\end{abstract}

Key Words Expatriate adjustment; Intent to return early; Language proficiency; Predeparture knowledge; Culture novelty; Willingness to Communicate 


\section{Introduction}

'In the era of global competition, the role of managers who are sent abroad for temporary assignments has become increasingly important especially for multinational companies (MNCs)' (Aycan, 1997: 434).

In today's global economy, it is critical to acquire, develop, and retain employees who possess global knowledge and experiences. They are the intellectual capital and key resources to create, maximize, and possibly sustain a company's competitive advantage (Black and Gregersen, 1999). Recognizing this, organizations have utilized several methods to help their employees acquire global knowledge and experiences. One of them is to have employees work in multicultural groups where team members have diverse cultural backgrounds (Adler, 1997) or place them in multinational teams that are geographically dispersed (Hambrick, Davidson, Snell, and Snow, 1998). The more direct, and perhaps, effective way is to place their employees on international assignments (Iwauchi 1992a, 1992b; Jinnouchi 1992). Perhaps it is not surprising then that the number of expatriates sent overseas has increased over the past decade and the trend is likely to continue (Mervosh and McClenahen, 1997), despite the high costs often associated with such assignments.

However, not all companies and all the expatriates are successful or effective in managing the entire process (Forster, 1997). Although estimates of expatriate failure rate, referred to a situation where an expatriate is recalled or voluntarily returns to the parent company before the end of assignment period (Dowling, Welch, and Schuler, 1999), may not be as high as previous thought (e.g., Forster, 1997; Foster and Johnsen, 1996; Harzing, 1995), it only represents 
the tip of an iceberg of problems that can accompany international assignments such as sub-optimal performance (Harzing, 1995) or withdrawal behaviors during and after assignments (Forster, 1997). Furthermore, expatriate failure is associated with significant direct, as well as, indirect costs. Direct costs of failure have been estimated at $\$ 250,000$ to $\$ 1.25$ million per employee (Mervosh and McClenahen, 1997). Indirect costs of failure may include loss of self-esteem, selfconfidence, and prestige among one's peers, and reduced motivation and unwillingness to provide support to other expatriates (e.g., mentor, trainer, and social supporter). Moreover, at the corporate level, indirect costs may range from expatriate turnover, reduced productivity for the foreign subsidiaries due to a decrease in local morale, lost opportunities for creating or penetrating the market, and relational difficulties with host country stakeholders (e.g. government officials and clients) (Dowling et al., 1999). Thus, it is imperative to understand the causes of these failures and to learn ways to both minimize and avoid them. This study intends to help organizations find a way to reduce the failure of the international assignment by improving our understanding of the adjustment process for expatriate managers in more detail.

To date, most research has focused primarily on factors that lead to adjustment, with less emphasis on examining the consequences of adjustments (McEvoy and Parker, 1995). Typically, adjustment is often considered a dependent variable (see Black, Mendenhall, and Oddou, 1991), even though it is frequently considered the key intervening or mediating factor leading to failure (e.g., Adler, 1997; Dowling et al., 1999). As 'McEvoy and Parker (1995)’ noted 
in their review, consequences of adjustment have received very little attention, yet they are clearly important. This study builds on previous research by examining the mediating or intervening role of expatriate adjustment between four antecedent factors (language proficiency, previous knowledge, willingness to communicate, and culture novelty) and intent to return early. The main objective of the present study was to examine the roles of expatriate adjustment and its consequences.

\section{Expatriate Adjustment}

Cross-cultural adjustment, in general, has been conceptualized as the degree of psychological adjustment experienced by an individual, or the degree of comfort, familiarity, and ease that an individual feels toward the new cultural environment (e.g. Church, 1982; Mendenhall and Oddou, 1985; Ruben and Kealey, 1979). 'Black and his colleagues (Black, 1988, 1990; Black and Gregersen, 1991a, 1991b; Black and Stephens, 1989)' have proposed and found support for the multidimensionality of expatriate adjustment, which consists of three factors (general, work, and interactional adjustment). General adjustment refers to the psychological comfort involving the host cultural environment such as weather, food, and living conditions; work adjustment is more specific and refers to the psychological comfort regarding different work values, expectations, and standards; and interactional adjustment focuses on adjustment to different communication styles in the host culture and to interpersonal communication with the host country nationals (e.g., Black, 1990; Black and Stephens, 1989). The 
multidimensional conceptualization of adjustment seems logical, given the multidimensional conceptualization of culture (e.g. Hofstede, 1980) and empirical supports (e.g., Florkowski and Fogel, 1999; Robie and Ryan, 1996; Shaffer and Harrison, 1998).

\section{Factors Related to Expatriate Adjustment}

Individual factors such as tolerance for ambiguity or stress (Hammer, Gudykunst, and Wiseman, 1978; Ruben and Kealey, 1979; Stening and Hammer, 1992) and non-ethnocentrism (Black, 1991a; Hawes and Kealey, 1981; Nishida, 1985) have been found to influence cross-cultural adjustment. In addition to these factors, evidence suggests that an expatriate's communication and/or interpersonal skills (Abe and Wiseman, 1983; Hawes, and Kealey, 1981; Nishida, 1985; Ruben and Kealey, 1979; Stening and Hammer, 1992) are salient factors that may affect all facets of adjustment. Language proficiency, previous knowledge of the host culture, and willingness to communicate were chosen, based on previous research findings for the individual.

As noted above, communication skills are an important factor in crosscultural adjustment. 'Mendenhall and Oddou (1985)' concluded that language skills are a means to create and foster interpersonal relationships and understand the dynamics of a new culture; hence, they are useful in expatriates' adjustment. One cannot, however, be effective in communicating unless a person is fluent in the host country's language. For example, the more proficient one is in the host 
country's language, the easier it may be to obtain necessary information, such as where and how to purchase certain commodities, use different means of transportation (bus, taxi, train, etc.), or simply ask for directions. Thus, it is expected that:

Hypothesis 1a: Expatriate's host cultural language proficiency will be positively related to general adjustment.

In addition, language proficiency helps one to communicate with coworkers. This, in turn, leads one to learn the appropriate work values, expectations, and standards used at work more efficiently and easily, which helps expatriates to behave accordingly and appropriately at work. This would especially be true in a situation where an employee moves from a high context culture to a low context culture or vice versa. 'Hall (1976)' differentiates cultures on the basis of communication that predominates in the culture. In a high context culture (such as Japan), people make greater distinctions between insiders and outsiders than low-context cultures do. However, even in a low-context culture such as the U.S., the outsider-insider distinction affects the interactions at work, such as the quality of leader-member exchange (LMX: Graen, 1976; Graen and Uhl-Bien, 1995). The LMX research has found that LMX is related to communication frequency (e.g., Graen, 1976) and communication pattern differences (Fairhurst and Chandler, 1989). Inabilities to speak the "language” will likely place individuals in the outsider group and have lower quality LMX, which has been found to be associated with harsh job climate (Dunegan, UhlBien, and Duchon, 1992), lower job satisfaction (Stepina, Perrewe, and Hassell, 1991), and higher turnover (Ferris, 1985). Thus, lack of language proficiency can 
be expected to negatively affect work adjustment. Conversely, being fluent in the host cultural language accords better opportunities for individuals to become part of the group and enjoy a better job climate. Thus, the following is to be expected:

Hypothesis 1b: Expatriate's proficiency in host language will be positively related to work adjustment.

Similarly, language proficiency may enable individuals to learn the subtle interpersonal communication norms, rules, and roles (Gudykunst and TingToomey, 1988). For example, Japan has a high power distance culture - the extent to which the less powerful members of institutions and organizations accept that power is distributed unequally (Hofstede and Bond, 1984) - with different norms when communicating with seniors than with equals. If expatriates in Japan do not know or understand these implicit norms, they will not be effective in communicating with the host country nationals. However, if expatriates are more fluent in the host culture's language, it will be easier to learn these rules and behave accordingly. In other words, when a person is fluent in the host country's language, it may smooth the interpersonal communications between an expatriate and host country national, which leads to better adjustment. Also, in nature, language is at the center of individual interactions. Expatriates who speak the host country's language fluently are more likely to feel comfortable to engage in the interaction with the host nationals. Therefore, a positive effect of language proficiency on interactional adjustment is expected.

Hypothesis 1c: Expatriate's host cultural language proficiency will be positively related to interactional adjustment. 
Previous knowledge or predeparture knowledge (Black, 1988; Black, 1990; Tung, 1988) of the host culture is considered to be another important individual factor that leads to successful adjustment (e.g., Black, 1988; Tung, 1988). Previous knowledge about the host culture can be acquired through several means, including prior experience in the host country. It can also be acquired through cross-cultural training (Selmer, Torbiorn, and de Leon, 1998), books, and interactions with people from the host culture. The more expatriates know about the host culture, the more accurate their expectations will be (Caligiuri, Phillips, Lazarova, Tarique, and Bürgi, 2001). 'Caligiuri and colleagues (2001)' found met expectations to be positively related to adjustment to host culture in general. Thus, the researchers formulate the following:

Hypothesis 2a: Expatriates' previous knowledge of the host culture will be positively related to general adjustment.

Given the multitude of knowledge on social customs, business practices, and communicative and social behaviors appropriate in the host country, the more knowledge expatriates have about business practices and social customs, the easier it is for them to acquire appropriate attitudes and behaviors and to get socialized at work. It is also more likely to facilitate interpersonal relations at work. Host country nationals can provide valuable information as to the appropriate attitudes and behaviors at work, which may be different from the general customs. Thus, knowing appropriate business practices and norms prior to going abroad facilitate this socialization process. Hence, the following can be expected: 
Hypothesis 2b: Expatriates' previous knowledge of the host culture will be positively related to work adjustment.

Similarly, knowing the appropriate conduct when interacting with the host country nationals is important. In interpersonal interaction, verbal, as well as nonverbal, behaviors differ widely across cultures (Gudykunst and Ting-Toomey, 1988). For instance, proxemics - the use of interpersonal space or distance to regulate intimacy by controlling sensory exposure - differs widely across cultures (Hall, 1976). The need for close space is particularly high for Arabs but low for North Americans, for example. Thus, in an international assignment to Arabic countries, if a North American keeps distance away from an Arab while talking, the Arab will be likely to think that the North American is cold and uninterested, which will lead to negative emotions. However, if a North American knew the need for closer physical space for Arabs, s/he can behave accordingly, which leads to better interpersonal relations. Hence, the following:

Hypothesis 2c: Expatriates' previous knowledge of the host culture will be positively related to interactional adjustment.

Similarly, 'Mendenhall and Oddou (1995)' concluded that the willingness to communicate is an important predictor of cross-cultural adjustment. Language proficiency may be a necessary, but not a sufficient, condition for cross-cultural adjustment. This appears to be the case, especially in learning the intricacies of intercultural communication (Gudykunst and Ting-Toomey, 1988; Iwauchi, 1992b). Hence, the researchers expect the following:

Hypothesis 3a, 3b, 3c: Expatriates' willingness to communicate will be positively related to general, work, and interactional adjustment, respectively. 
Culture novelty (Black et al., 1991), culture toughness (Mendenhall and Oddou, 1985), or culture distance (Church, 1982) refers to the cultural differences between the host culture that an expatriate is assigned to and the home culture from which an expatriate comes. As conceptualized in the literature (e.g., Black et al., 1991), culture novelty refers to the subjective notion of this cultural difference between the host and the home culture.

"Although there is ample evidence that cultural differences can act as considerable barriers to business expatriates” (Selmer, 2001: 154), the empirical results of the effects of perceived culture novelty on adjustment have been limited and equivocal (Black and Stephens, 1989; Black and Gregersen, 1991a; Parker and McEvoy, 1993) and further research seems warranted. The logic for the importance of perceived culture novelty as a predictor of adjustment, however, is straightforward. For example, if an American expatriate is assigned to New Zealand, a country with a similar overall culture to that of the U.S. (Hofstede, 1980), the expatriate's perceived culture novelty is likely to be low. The behaviors expected in the New Zealand will be much more similar than those in a country that has a much more dissimilar culture to that of the U.S. Therefore, relatively speaking, the less culturally novel an expatriate's perception of the host culture is, the less effort the expatriate needs to adjust to the host culture. Thus, the following is expected:

Hypothesis 4a, 4b, and 4c: Perceived culture novelty will be negatively related to expatriates' general, work, and interactional adjustment.

In addition to the direct relationship between previous knowledge and adjustment, previous knowledge is also related to culture novelty in nature. As 
people tend to evaluate the host culture based on their knowledge, people who have more knowledge of the host culture (e.g., previous experience in the host country or an exposure to people from the host country) are more likely to be familiar with it than others. This is in accordance with the typical operationalization of culture novelty as an individual subjective comparative assessment of the similarities or differences of the host culture to that of the home culture (e.g., Black and Stephens, 1989; Black and Gregersen, 1991a, 1991b; Shaffer and Harrison, 1998).

When an expatriate has more knowledge of the host culture, which indicates that s/he had more exposure to the host culture through direct (e.g., previous work experience) or indirect (e.g., training, having a friend from the host culture, and learning) experiences, the less culture novelty he/she perceives. However, if an expatriate has little knowledge and information on the host country, s/he is more likely to feel the host country's culture novel and strange. Thus, it is expected that the previous knowledge of the host culture will reduce the novelty of the host culture. Therefore, the following hypothesis was formulated:

Hypothesis 5: An expatriate's previous knowledge of the host culture is negatively related to perceived novelty of the host culture.

The Interrelationships among Adjustment

Although three facets of cross-cultural adjustment advanced by Black and colleagues appear to be well acknowledged, there has been a lack of research that examined the relationships among the adjustment dimensions. More recently, 
Aycan (1997) argued, "psychological and socio-cultural [general] adjustment are the most immediate predictors of work adjustment" (434). We extend this framework to include interactional adjustment.

Despite the lack of empirical research that examines the interrelationships among adjustment factors, there seems to be a general consensus that adjusting to interactional differences are the most difficult aspects of cross-cultural adjustment (e.g., Black, Gregersen, Mendenhall, \& Stroh, 1999; Mendenhall and Oddou, 1985) because it entails much more complexities and subtleties.

When people acquire language, they do not learn language per se. Rather, they learn the various patterns and styles of interpersonal interactions that enable them to function as competent communicators in different situational contexts (Gudykunst and Ting-Toomey, 1988). General environment seems to require the least amount of language fluency. For instance, one only needs a "basic" level of language proficiency in order to live in a foreign environment. In addition, people generally have more control over their surroundings, which makes it easier for them to become comfortable with the surroundings. Thus, general adjustment is expected to be the easiest facet. Also, even though the primary reason for sending employees overseas is work assignment, an expatriate cannot perform the task without satisfying the basic needs, such as foods and the like. In other words, when an expatriate is well adjusted to the general environment, s/he is more likely to spend time getting involved in the work. As a result, we expect the general adjustment to have a positive influence on work adjustment.

Hypothesis 6: General adjustment is positively related to work adjustment. 
Finally, effective interpersonal interaction requires not only language proficiency, but also an understanding of appropriate behaviors. When an expatriate is well adjusted to the work, which is a primary reason for the overseas assignment, s/he can spend more time acquiring behaviors appropriate for interpersonal interaction beyond work-related conversations. As a result, the following is expected:

Hypothesis 7: Work adjustment is positively related to interactional adjustment.

\section{The Relationship of Adjustment to Outcomes}

The consequences of adjustment have received limited attention, yet they are clearly important for the organization (McEvoy and Parker, 1995). Understanding the consequences of adjustment may provide the organization with ways to devise human resources practices and policies that reduce the number of expatriate failures, which has beneficial effects both on the organization and the individuals concerned. In the current study, the researchers focus particularly on intent to return early. An important consequence of adjustment for organizations is an expatriate's intent to terminate the international assignment early and return home. Early return indicates a failure of the international assignment in the host location. In this paper, intent to return early was chosen as our focal outcome variable due to its theoretical and practical importance for organizations sending their employees on international assignments. 
Hypothesis 8: General adjustment will be negatively related to intent to return early.

Hypothesis 9: Work adjustment will be negatively related to intent to return early.

Hypothesis 10: Interactional adjustment will be negatively related to intent to return early.

Figure 1 provides the overall framework for all of the hypothesized relationships.

Insert Figure 1 about here

\section{Method}

Research Design

An executive director of a chapter of Japan-America Society, an association that provides services to companies associated with Japanese-American international trade, was initially contacted to solicit involvement of the Society for this research. After an enthusiastic endorsement provided by the director, the primary researcher presented the Board of Executives with research objectives to secure further participation. In total, 55 companies agreed to participate in the project. They also provided the names of 298 Japanese expatriates, their home addresses, phone numbers, and marital status. Participating companies represented a range of industries, although many of them were connected to automobile manufacturing. The industries included auto repairs, chemical extraction, gas, electrical equipment, miscellaneous repair \& services, primary metal, wholesale trade, and wholesale trade: non-durable goods, among others. The companies who participated in the study are listed in Table 1.

Insert Table 1 about here 


\section{Sample}

Surveys were sent to all of the expatriates from the 55 companies in various industries to their home addresses with a cover letter from the researchers explaining the purpose of the project and an endorsement letter from the executive director encouraging participation in the research. The respondents were also asked to provide the name of a superior who knew the respondent well. In total, 243 questionnaires were returned by the expatriate after a postcard reminder. The response rate was $81 \%$. Approximately 10 days after the initial expatriate survey distribution, surveys were sent to spouses $(n=200)$ using the same procedure. Out of 200 spouses, 173 returned the spouse survey. The response rate of spouses was $86.5 \%$. The response rate for the survey is much higher than those in previous studies in the expatriate literature (e.g., 40\%: Black, 1988; 22\%: Black and Gregersen, 1991a; 71\%: Guzzo, Noonan, and Elron, 1994; 63\%: Parker and McEvoy, 1993; 41.5\%: Shaffer and Harrison, 1998). The higher response rates were obtained due to combination of factors: use of Japanese surveys, considerable interest shown by the company representatives, active encouragement from both the director of the association and the company representatives, and a promise of a written report.

Note that the respondents used in this study were 170 Japanese expatriates working in the U.S. with spouses. Variables included are a subset of the larger research effort to understand expatriate adjustment. In this sample, all expatriates were male, $99 \%$ of the expatriates were married (2 cases were separated or in the 
process of separation); $78 \%$ of the expatriates had a bachelor's degree or a higher level degree; $74.3 \%$ were in management positions (ranging from entry-level to top executives); 37.4\% were in technical positions; $61 \%$ had previous overseas work experience; and 73\% had at least one child living with them. The mean age of expatriates was 39 years (range: 27 to 61 years) with 11 years of organizational tenure (range: 2 to 439 months). They have been in the U.S. for 33 months on average (range: 1 to 110 months). For the spouses, 59\% had at least an associate degree (25\% with a bachelor's degree or a higher degree), $62 \%$ were working prior to coming to the U.S., $11 \%$ currently work, and $11 \%$ had prior overseas work experience. The mean age of spouses was 36 years (range: 22 to 58 years) and they have been in the U.S. for 31 months on average (range: 1 to 106 months). The demographics of this matched sample are comparable to those of previous studies (e.g., Black, 1988; Gregersen and Black, 1992; Guzzo et al., 1994; Shaffer and Harrison, 1998).

Shortly after expatriates returned the questionnaire, the primary researcher conducted brief telephone interviews with the superiors to obtain their assessments of expatriates' work adjustment. Three work adjustment items developed by 'Black and Stephens (1989)' were used. The telephone interview was kept under 10 minutes in an attempt to maximize the responses. Thus, the researchers were able to obtain superior ratings from all 243 responses. However, this prevented the primary researcher from obtaining other information on the superiors. 
Measures

Most of the variables were measured on a seven-point Likert scale, unless otherwise noted. The response format was labeled as follows: “1” = strongly disagree, "2" = moderately disagree, “3” = slightly disagree, “4” = neutral, “5” = slightly agree, “6” = moderately agree, and “7” = strongly agree.

Language proficiency Initially, individuals' proficiency in English was measured objectively by the test scores on the Test of English as a Foreign Language (TOEFL), as well as subjectively. However, this objective measure of language proficiency was dropped because only 11 respondents had taken TOEFL prior to coming abroad. Five items that asked respondents on their degree of confidence in using English was used to assess their language proficiency. The items were "I feel confident in: 1) using English in general, 2) writing in English, 3) speaking English, 4) reading and understanding English, and 5) listening to English.” Cronbach’s alpha for this measure was .97, suggesting internal consistency.

Previous knowledge Four items from the 5-item predeparture knowledge scale used by 'Black (1990)' were adopted. An item that assessed the understanding of English language was not used due to anticipated confound with the language proficiency items. A sample item stated, "I had sufficient knowledge of American 
social customs before coming to the U.S.” Cronbach's alpha for this scale was .93, also suggesting internal consistency.

Willingness to communicate The researchers also adopted two items for willingness to communicate from the review provided by 'Mendenhall and Oddou (1985).' These items were: 1) 'I am trying to interact with people in the host country," and 2) "I intend to understand and relate with host nationals, as much as possible.” The Cronbach’s alpha for this scale was .90.

Culture novelty Two items from 'Black and Stephens (1989)' culture novelty scale that were adopted from 'Torbiorn (1982)' were used. The items were: "everyday customs that must be followed in the U.S. are similar to those in the home country" and "general living conditions in the U.S. are similar to those of the home country.” These items were reverse coded to be in line with the culture novelty concept. The reliability for this scale was .78.

Adjustment General, work, and interactional adjustment were measured using a 14-item adjustment scale developed by 'Black (1990).' In order to reduce one source of common method biases, the three facets of adjustment were assessed from different sources. We chose the source deemed most appropriate, i.e., expatriate's general adjustment was assessed by the spouses, work adjustment by the superiors, and interactional adjustment by the expatriates themselves. Out of the 14 items used, seven items were designed to measure general adjustment, 
three items for work adjustment, and four items for interactional adjustment. 'Robie and Ryan (1996)' established the factor structure of the scale by using confirmatory factor analysis and structural equivalence of this scale for different nationality samples.

The spouses provided their assessments of the expatriates' general adjustment with a reliability of .84 . In order to assess the validity of spousal assessment of expatriate general adjustment, the researchers correlated it with expatriate's self-rating of general adjustment. Spousal assessment correlated significantly with that of expatriate's self-ratings $(r=.48, \mathrm{p}<.001)$, providing evidence for the convergent validity of the spousal rating. To reduce the potential for same respondent bias, the spousal assessment of expatriate's general adjustment in this study was used. A sample item stated, "Please circle the number that best describes your assessment regarding your spouse's adjustment to the following item: 'living condition in general.”' The anchors ranged from 1 (not very well adjusted) to 7 (very well adjusted).

Similarly, the researchers obtained ratings of work adjustment from superiors who were familiar with the expatriate's work over the phone. Superior ratings are generally considered a valid alternative to self-ratings in the performance appraisal literature when the supervisor has the opportunity to observe the employee (Atwater, Ostroff, Yammarino, \& Fleenor, 1998). Supervisors were asked to indicate the number that best described their assessment regarding the expatriate employee's adjustment to the work related 
items. One of the sample items was "specific job responsibilities.” The reliability of this scale was .81.

Interactional adjustment ratings were used, which were assessed by the expatriate, although spouses evaluated expatriate's interactional adjustment as well. Given that two of the four items for interactional adjustment refer to a situation at work, a significant number of spouses $(n=54)$ could not respond to these items. Thus, the responses given from the spouses may be a less valid source of interactional adjustment. Despite a significant correlation between spousal assessments of expatriate's interactional adjustment with the expatriate's own evaluation $(\mathrm{r}=.44, \mathrm{p}<.001)$, significant reduction in the sample size $(\mathrm{n}=$ 119) limited the use of the spousal assessment as an alternative rating source. The researchers retained the expatriate's self-ratings for interactional adjustment ( $\alpha=$ .87), which may be a more valid rating source than that of the spouses. Given that the items ask both work and non-work interactions, it is believed that expatriate's self-ratings of interaction adjustment are more valid in this case.

Intent to return early Two items were adopted from 'Black and Stephens (1989)' scale and another item was developed to assess the expatriate's intent to return early. The following three items were used: "I will do anything to keep this assignment for its expected duration (reverse coded)," "I discussed the possibility of returning home early with my spouses," and "I think about going home before the assignment is over.” The first item was dropped from subsequent analyses due to poor reliability. The resulting two-item scale had a reliability of .81 . 


\section{Analyses}

First, first-order and second-order confirmatory factor analyses (CFA) were conducted on the adjustment items to assess the appropriateness of three-factor conceptualization of expatriate adjustment and the existence of higher order adjustment factor. Each of the 14 items was constrained to load on their hypothesized factors, and then these three factors were constrained to load on a common, adjustment construct. Appendix A provides the results of the secondorder CFA. The model fit indices were acceptable $\left(\chi^{2}=95.75\right.$ with $71 \mathrm{df}$, Comparative Fit Index $[\mathrm{CFI}]=$.98, Standardized Root Mean Residual $[$ SRMR $]=$ .05). Both CFI and SRMR exceeded the recommended value of greater than .96 and less than .1 (Bentler, 1995; Hu and Bentler, 1999). All 14 items loaded significantly $(\mathrm{p}<.001)$ onto theoretically relevant dimensions. Furthermore, all three loaded significantly onto a common, higher-order factor, Expatriate Adjustment. This result confirms the validity of the items and the threedimensional (general, work, and interactional adjustment) conceptualization of expatriate adjustment.

Next, Structural Equation Modeling (SEM) analyses were used to test the hypotheses. EQS for Windows 5.7b (Bentler, 1998) version was used. Due to sample size limitation for a recommended ratio of at least 5 sample size to 1 number of free parameters to be estimated for normally or elliptically distributed variables (Bentler, 1995), we used the reliability correction method, as outlined by Jöreskog and Sörbom [1989]. In other words, we first fixed all factor loadings 
with the square root of the reliability of the composite scale and the measurement errors with the unreliability multiplied by the variance) and used the scales as indicators for the structural models. The means, standard deviations, Cronbach's alpha coefficients for the scales, and intercorrelations of the variables used in these analyses appear in Table 2.

Insert Table 2 about here

\section{Results}

\section{Structural Equation Modeling}

Standardized path coefficients and the significance of each path are shown in Figure 2. Only the significant paths are drawn. In general, the results of this model show that it is very consistent with the data $\left(\chi^{2}=21.10\right.$ with $9 \mathrm{df}, \mathrm{p}<.1$; AIC $=3.10 ;$ CFI $=.97 ;$ and SRMR $=.06$ ). The CFI was .97 and SRMS was .06 , both exceeding the recommended combination cutoff points of above .96 for CFI and less than .1 for SRMS, advocated by 'Bentler (1995)' and his colleagues (Hu and Bentler, 1999). The covariances included were all significant at $\alpha<.05$.

It was hypothesized that there would be positive relationships between language proficiency and the three facets of expatriate adjustment (Hypotheses 1a-1c). Language proficiency was significantly, positively related to work adjustment $(\beta=.35, \mathrm{p}<.05)$, but not to general or interaction adjustment. These results support Hypothesis 1b. Hence, being proficient in the host cultural language is related to higher levels of work adjustment. 
Hypotheses 2a-2c suggest positive relationships between previous knowledge and the three facets of expatriate adjustment (general, work, and interaction). Previous knowledge was significantly, positively related to general adjustment $(\beta=.39, \mathrm{p}<05)$, supporting Hypothesis 2a. It was also significantly, positively related to interaction adjustment $(\beta=.27, \mathrm{p}<.05)$, supporting Hypothesis 2c. However, it was not related to work adjustment (Hypothesis 2b). Thus, previous knowledge about the host country is related to higher levels of general and interactional adjustment.

Willingness to communicate was positively related to interactional adjustment $(\beta=.13, \mathrm{p}<.05)$, which provides support for Hypothesis 3c. However, it was not significantly related to either general or work adjustment.

Culture novelty was negatively related to work adjustment $(\beta=-.17, \mathrm{p}<$ .1), but not to general or interactional adjustment. In addition, the result provided support for Hypothesis 5, which proposed a negative relationship between previous knowledge and culture novelty $(\beta=-.45, \mathrm{p}<.01$ ), indicating that having prior information about the host culture is related to perceiving the host culture as less novel.

Hypothesis 6 predicted a positive relationship between general and work adjustment such that being more adjusted to general environment has a positive influence on the level of work adjustment. The result of the analysis suggests that this is likely to be the case $(\beta=.25, \mathrm{p}<.01)$, thereby providing support for Hypothesis 6. Similarly, Hypothesis 7 that predicted a positive relationship between work and interactional adjustment was supported $(\beta=.56, \mathrm{p}<.001)$. 
Finally, Hypotheses 8, 9, and 10 proposed a negative relationship between the three facets of adjustment and intent to return early. The results provide support for Hypothesis $8(\beta=-.16, \mathrm{p}<.1)$ and Hypothesis $9(\beta=-.53, \mathrm{p}<.01)$ such that both general and work adjustments appear to reduce expatriates' early return intention. The results of the SEM analysis are depicted in Figure 2.

\section{Insert Figure 2 about here}

\section{Discussion}

In this study, the researchers investigated the role that expatriate adjustment plays during international assignments. Three individual-level antecedent variables (language proficiency, previous knowledge, and willingness to communicate) considered important for adjustment were included along with an outcome variable (intent to return early). In addition, the interrelationships among the adjustment factors were examined. The findings of this study are consistent with the proposed model of expatriate adjustment and provide empirical evidence for the critical role that adjustment plays during the international assignments.

More specifically, it was found that language proficiency was positively related to work adjustment, previous knowledge to both general and work adjustments, and willingness to communicate to interactional adjustment. Interestingly, all three variables correlated significantly to all three facets of adjustment with the exception of willingness and work adjustment (See table 2). Perhaps, the relationships among these variables are more complicated than that captured in the analysis, which may imply that they interact with one other to 
influence levels of adjustment. One future direction of expatriate adjustment research may be to examine these phenomena from a nonlinear perspective (Mendenhall and Macomber, 1997), such as examining the interaction among the antecedent variables.

The results indicate that there is discriminant validity among the individual-level antecedent variables in the context of SEM. Previous knowledge had direct influence on general and interaction adjustments, as well as an indirect effect on work adjustment through culture novelty, whereas language proficiency had a direct effect on work adjustment and an indirect effect on interactional adjustment through work adjustment. Willingness to communicate, on the other hand, had a direct effect only on interactional adjustment. Perhaps, language proficiency is more important for work and interpersonal interactions at work for expatriate employees, but less important for general adjustment. To feel comfortable with the general environment, perhaps one only needs the survival level of language proficiency that allows an individual to satisfy basic needs such as getting food, drink, and water, and securing housing and acceptable living conditions. Being proficient in the host cultural language may be more important when individuals interact and relate with others at work.

This study demonstrated the importance of previous knowledge, language proficiency, and willingness to communicate on expatriate adjustment process. These results recommend that organizations develop programs to help their employees prepare for international assignments. Future research needs to 
identify the programs organizations can utilize and evaluate the effectiveness of those programs.

The effects of culture novelty were less consistent in its relationship to adjustment, although correlations between novelty and adjustment were more consistent. Culture novelty was only marginally related to work adjustment. It may be that work was more central to this sample of expatriates such that culture novelty only affected their reactions toward work. Perhaps, the effect of culture novelty is more complex than that captured by linear conceptualization (cf. Mendenhall and Macomber, 1997). Another future research direction may be to examine the relationship between culture novelty and adjustment as quadratic or cubic in shape, or the relationship between culture novelty and adjustment may be moderated by other variables, such as openness to experience and the like. Future research investigating this potential moderating relationship will benefit from this understanding of expatriate adjustment.

The most interesting findings may be associated with the three facets of adjustment. As argued by Aycan (1997), the results suggest that being welladjusted to the general environment has a positive influence on work adjustment, which, in turn, influences the level of interactional adjustment. Perhaps being well-adjusted in one aspect frees up more resources, such as energy and time for the expatriates, so that they can utilize these resources at work or in interactions with host nationals. If the results are replicated, it has significant implications for expatriate management. 
The contributions of the current study, however, must be assessed in light of its limitations. The same respondents assessed many of the variables at one point in time with a survey. Thus, the same respondent bias and the common method bias may be a concern. However, the current study used three ratings sources (expatriates, spouses, and superiors) for the key adjustment variables to reduce the same respondent bias. Moreover, a different data collection method, phone survey, was utilized for ratings by superiors, which reduces the threat of common method bias further. In addition, if same respondent bias or common method bias was in effect and inflated the correlations among the variables, the self-rated interactional adjustment should have a stronger effect on self-rated intent to return early, which was not the case. Thus, the concern for same respondent bias or common method bias is reduced further.

Another limitation may be the 2-item scale utilized for culture novelty. Given the multidimensionality of culture (e.g., individualism/collectivism, masculinity/femininity, power distance, uncertainty avoidance: Hofstede, 1980), culture novelty is likely to be multidimensional as well. In retrospect, the items used to assess culture novelty appear to be deficient in capturing this multidimensionality. Perhaps future research can develop a new and an improved scale that assesses the multidimensional aspect of culture novelty. With a better measurement tool, future research may be able to assess the potential for mediating or moderating effects of culture novelty more accurately.

It may also be helpful to include other attitudinal variables (e.g., parent company and foreign subsidiary commitment: Gregersen \& Black, 1992) that are 
specific to the international assignment context. Furthermore, it would be very useful for future research to include additional variables that the organizations have control over to facilitate expatriate adjustment. For example, providing organizational support may have direct effects on the level of adjustment at the host country, whereas providing predeparture training may increase the knowledge that an expatriate has before leaving the home country.

\section{Practical Implications}

The study demonstrates the importance of work adjustment to the well being of the expatriates and in reducing their intention to prematurely terminate the assignment. As shown by the relationship between work adjustment and intention to return early, it is imperative that corporations take necessary measures to make expatriates become better adjusted at work. Various organizational support mechanisms, such as assigning host country nationals who are fluent in the home language of the expatriates as mentors, or extending psychosocial support by introducing the expatriates to other expatriates with extensive experience in the host locale, may be very effective. In a similar vein, creating a network of expatriates for emotional and social support may be important. Obviously, providing predeparture training (to increase expatriates' language proficiency and knowledge of the host culture) can be an effective means of ensuring potential success. 
Also, the results provide some insights in selecting employees to be sent overseas. Organizations are recommended take careful steps in selection process. They need to consider not only the employee's capabilities to perform his/her tasks, but also they need to assess his/her knowledge of the host country and the expatriates' language proficiency. In addition, willingness to communicate needs to be taken in account.

\section{Conclusion}

This study attempts to deepen the understanding of expatriate adjustment. The mediating roles of expatriate adjustment were tested. In sum, the results suggest that expatriate adjustment is an important area of scholarly inquiry due to the substantial impact it has on the organization, as well as the individual. Perhaps, organizations can tailor their HR practices and policies (e.g., selection, training, and compensation) to reduce the number of expatriates who terminate their assignments early before accomplishing the objectives or assignments. By doing so, the organization may acquire a competitive advantage over its rivals who do not utilize their employees’ global talents properly. By deepening and expanding the understanding of the expatriate adjustment process, managers as well as scholars may gain critical knowledge for influencing the outcomes of international assignments. This study took one step further toward increasing the understanding of the expatriate adjustment process, albeit an incremental step, so 
Role of Expatriate Adjustment 31

that the collective knowledge gained from this stream of research can be used by the organization to improve its human resource practices. 


\section{References}

Abe, H. and Wiseman, R.L. (1983) 'Cross-cultural Confirmation of the

Dimensions of Intercultural Effectiveness', International Journal of Intercultural Relations, 7: 53-67.

Adler, N.J. (1997) International Dimensions of Organizational Behavior (3 ${ }^{\text {rd }}$ ed.). Cincinnati, OH: South-western College Publishing.

Atwater, L.E., Ostroff, C., Yammarino, F.J. and Fleenor, J.W. (1998) 'Self-other agreement: Does it really matter?’, Personnel Psychology, 51: 577-598.

Aycan, Z. (1997) 'Expatriate Adjustment as a Multifaceted Phenomenon: Individual and Organizational Level Predictors', International Journal of Human Resource Management, 8: 434-456.

Baron, R.M. and Kenny, D.A. (1986) 'The Moderator-Mediator Variable Distinction in Social Psychological Research: Conceptual, Strategic, and Statistical Considerations', Journal of Personality and Social Psychology, 51: $1173-82$.

Bentler, P.M. (1995) EQS Structural Equations Program Manual. Encino, CA: Multivariate Software, Inc.

Bentler, P.M. (1998) EQS for Windows 5.7b. Encino, CA: Multivariate Software, Inc.

Black, J.S. (1988) 'Work Role Transitions: A Study of American Expatriate Managers in Japan’, Journal of International Business Studies, 19: 27794. 
Black, J.S. (1990) 'Factors Related to the Adjustment of Japanese Expatriate Managers in America', Research in Personnel and Human Resources Management, Suppl. 2: 109-25.

Black, J.S. and Gregersen, H.B. (1991a) ‘Antecedents to Cross-cultural Adjustment for Expatriates in Pacific Rim Assignments. Human Relations, 44: 497-515.

Black, J.S. and Gregersen, H.B. (1991b) ‘The Other Half of the Picture: Antecedents of Spouse Cross-cultural Adjustment', Journal of International Business Studies, 22: 461-77.

Black, J.S. and Gregersen, H.B. (1999) 'The right way to manage expats', Harvard Business Review, 77(2): 52-63.

Black, J.S., Gregersen, H.B., Mendenhall, M.E., and Stroh, L.K. (1999) Globalizing People through International Assignments. Reading, MA: Addison-Wesley.

Black, J.S., Mendenhall, M., and Oddou, G. (1991) ‘Toward a Comprehensive Model of International Adjustment: An Integration of Multiple Theoretical Perspectives’, Academy of Management Review, 16: 291-317.

Black, J.S. and Stephens, G.K. (1989) 'The Influence of the Spouse on American Expatriate Adjustment and Intent to Stay in Pacific Rim Overseas Assignments', Journal of Management, 15: 529-44.

Caligiuri, P.M., Phillips, J., Lazarova, M., Tarique, I. and Bürgi, P. (2001) ‘The theory of met expectations applied to expatriate adjustment: The Role of 
Cross-Cultural Training', International Journal of Human Resource Management, 12: 357-372.

Church, A.T. (1982) 'Sojourner Adjustment’, Psychological Bulletin, 9: 540-72.

Dowling, P.J., Welch, D.E. and Schuler, R.S. (1999) International Human Resource Management: Managing People in a Multinational Context (3rd ed.). Cincinnati, OH: South-Western College.

Dunegan, K.J., Uhl-Bien, M. and Duchon, D. (1992, August) Task-level climate and LMX as interactive predictors of performance. Paper presented at annual meeting of the Academy of Management, Las Vegas, NV.

Fairhurst, G.T. and Chandler, T.A. (1989) 'Social Structure in Leader-Member Exchange Interaction’, Communication Monograph, 60: 321-51.

Ferris, G.R. (1985) 'Role of Leadership in the Employee Withdrawal Process: A Constructive Replication', Journal of Applied Psychology, 70: 777-81.

Florkowski, G.W. and Fogel, D.S. (1999) ‘Expatriate Adjustment and Commitment: The role of Host-Unit Treatment', International Journal of Human Resource Management, 10: 783-807.

Forster, N. (1997). 'The persistent myth of high expatriate failure rates': A reappraisal', International Journal of Human Resource Management, 8: 414-433.

Forster, N. and Johnsen, M. (1996) 'Expatriate Management Policies in UK Companies New to the International Scene', International Journal of Human Resource Management, 7: 179-205. 
Graen, G. (1976) ‘Role-making Processes within Complex Organizations’. In M.

D. Dunnette (ed.), Handbook of Industrial and Organizational Psychology (pp.1201-45). Chicago: Rand McNally.

Graen, G.B. and Uhl-Bien, M. (1995) 'Relationship-based Approach to Leadership: Development of Leader-Member-Exchange (LMX) Theory of Leadership over 25 Years: Applying a Multi-level Multi-domain Perspective’, Leadership Quarterly, 6: 219-47.

Gregersen, H.B. and Black, J.S. (1992) ‘Antecedents to Commitment to a Parent Company and a Foreign Operation', Academy of Management Journal, 35: 65-90.

Gudykunst, W.B. and Ting-Toomey, S. (1988) Culture and Interpersonal Communication. Newbury Park, CA: Sage.

Guzzo, R.A., Noonan, K.A. and Elron, E. (1994) 'Expatriate managers and the psychological contract', Journal of Applied Psychology, 79: 617-626.

Hall, E.T. (1976) Beyond Culture. New York: Doubleday.

Hambrick, D.C., Davidson, S.C., Snell, S.A. and Snow, C.C. (1998) 'When Groups Consist of Multiple Nationalities: Toward a New Understanding of the Implications’, Organization Studies, 19: 181-205.

Hammer, M.R., Gudykunst, W.B. and Wiseman, R.L. (1978) 'Dimensions of Intercultural Effectiveness: An Exploratory Study’, International Journal of Intercultural Relations, 2: 382-92.

Harzing, A.K. (1995) 'The Persistent Myth of High Expatriate Failure Rate', International Journal of Human Resource Management, 6: 457-474. 
Hawes, F. and Kealey, D.J. (1981) ‘An Empirical Study of Canadian Technical Assistance: Adaptation and Effectiveness on Overseas Assignment', International Journal of Intercultural Relations, 5: 239-58.

Hofstede, G. (1980) Culture's Consequences: International Differences in Workrelated Values (abridged edition). Newbury Park, CA: Sage.

Hofstede, G. and Bond, M. (1984) ‘Hofstede’s Culture Dimensions: An Independent Validation Using Rokeach’s Value Survey’, Journal of Cross-Cultural Psychology, 15: 417-33.

Hu, L. and Bentler, P.M. (1999) 'Cutoff Criteria for Fit Indexes in Covariance Structure Analysis: Conventional Criteria Versus New Alternatives’, Structural Equation Modeling: A Multidisciplinary Journal, 6(1): 1-55.

Iwauchi, R. (1992a). 'Zaigai-nikkei-kigyouno keieito kaigai-chuuzaiinno seikatsu [Management of overseas Japanese companies and the lives of expatriates]. In Kaigai-nikkei-kigyouto jinteki-shigen: Genchi-keieito chuuzai-inno seikatsu [Overseas Japanese corporations and human resources: Local management and the lives of expatriates] (pp. 1-14). Tokyo: Doubunkan.

Iwauchi, R. (1992b) ‘Kaigai-chuuzaiinno shigototo seikatsu [Content of work and lives of expatriates]’ In Kaigai-nikkei-kigyouto jinteki-shigen: Genchikeieito chuuzai-inno seikatsu [Overseas Japanese corporations and human resources: Local management and the lives of expatriates] (pp. 183-210). Tokyo: Doubunkan. 
Jinnouchi, Y. (1992) 'Kaigai-shijo-kyouiku-mondainimiru Nihonno kyouikutaishitsu [Japanese educational constitutions as evidenced by the problems associated with the education of the children of Japanese expatriates]'. In Kaigai-nikkei-kigyouto jinteki-shigen: Genchi-keieito chuuzai-inno seikatsu [Overseas Japanese corporations and human resources: Local management and the lives of expatriates] (pp. 211-236). Tokyo: Doubunkan.

Jöreskog, K.G. and Sörbom, D. (1989) 'LISREL VII: User’s Reference Guide’. Mooresville, IN: Scientific Software.

McEvoy, G.M. and Parker, B. (1995) 'Expatriate Adjustment: Causes and Consequences’. In J. Selmer (ed.), Expatriate Management: New Ideas for International Business (pp. 97-114). Westport, CT: Quorum Books.

Mendenhall, M. and Macomber, J.H. (1997) 'Rethinking the Strategic Management of Expatriates from a Nonlinear Dynamics Perspective’. In Z. Aycan (ed.), Expatriate Management: Theory and Research: Vol. 4 (pp. 41-62). Greenwich, CT: JAI Press.

Mendenhall, M. and Oddou, G. (1985) 'The Dimensions of Expatriate Acculturation: A Review', Academy of Management Review, 10: 39-47. Mervosh, E.M. and McClenahen, J.S. (1997) 'The Care and Feeding of Expats’, Industry Week, 246(22): 68-72.

Nishida, H. (1985) ‘Japanese Intercultural Communication Competence and Cross-cultural Adjustment', International Journal of Intercultural Relations, 9: 247-69. 
Parker, B. and McEvoy, G.M. (1993) 'Initial Examination of a Model of Intercultural Adjustment', International Journal of Intercultural Relations, 17: 355-79.

Robie, C. and Ryan, A.M. (1996) 'Structural Equivalence of a Measure of CrossCultural Adjustment', Educational and Psychological Measurement, 56: $514-21$.

Ruben, B.D. and Kealey, D.J. (1979) 'Behavioral Assessment of Communication Competency and the Prediction of Cross-Cultural Adaptation’, International Journal of Intercultural Relations, 3: 15-47.

Selmer, J. (2001) 'Psychological Barriers to Adjustment and How They Affect Coping Stratgies: Western Business Expatriates in China’, International Journal of Human Resource Management, 12: 151-165.

Selmer, J., Torbiorn, I. and de Leon, C.T. (1998) ‘Sequential Cross-Cultural Training for Expatriate Business Managers: Pre-Departure and PostArrival', International Journal of Human Resource Management, 9: 831840.

Shaffer, M.A. and Harrison, D.A. (1998) 'Expatriates' Psychological Withdrawal from International Assignments: Work, Nonwork, and Family Influences’, Personnel Psychology, 51: 87-118.

Stening, B.W. and Hammer, M.R. (1992) 'Cultural Baggage and the Adaption of Expatriate American and Japanese Managers', Management International Review, 32: 77-89. 
Stepina, L.P., Perrewe, P.L. and Hassell, B.L. (1991) 'A Comparative Test of the Independent Effects of Interpersonal, Task, and Reward Domains on Personal and Organizational Outcomes', Journal of Social Behavior and Personality, 6: 93-104.

Torbiorn, I. (1982) Living Abroad: Personal Adjustment and Personnel Policy in the Overseas Setting: Vol. 6. New York, NY: Wiley.

Tung, R.L. (1988) The New Expatriates: Managing Human Resources Abroad. Cambridge, MA: Ballinger Publishing Company. 
Table 1. List of Companies

\begin{tabular}{|l|l|}
\hline Aisin U.S.A. Manufacturing, Inc. & Kobelco Metal Powder of America \\
\hline Alpine Electronics MFG. of America, Inc. & KYB Industries, Inc. \\
\hline American TRS, Inc. & Marubeni Plant Contractor, Inc. \\
\hline Apollo America Corporation & M.C. Aluminum America, Inc. \\
\hline Arvin-Sango, Inc. & Mi-tech Steel, Inc. \\
\hline Cummins Komatsu Engine Co. & Moriden America, Inc. \\
\hline Diamet Corporation & Nachi Technology, Inc. \\
\hline Dowelanco & National Steel Corporation \\
\hline Elsa Corporation & Nippon Express U.S.A., Inc. \\
\hline Enkei America, Inc. & Nissin International Transport U.S.A., Inc. \\
\hline Femco Magnet Wire Corporation & Nissin Travel Service USA, Inc. \\
\hline Fuji Component Parts U.S.A., Inc. & NSK Corporation \\
\hline Fujitsu Ten Corporation of America & NYN Driveshaft, Inc. \\
\hline Gemco Corporation & Onkyo America, Inc. \\
\hline General Seating of America & Panasonic Industrial Company \\
\hline G.K.I. Corporation & PK U.S.A., Inc. \\
\hline H.A. Parts Products of Indiana Co. & Precision Tools Service, Inc. \\
\hline Heartland Automotive, Inc. & Ryobi Die Casting \\
\hline Heritage Products Inc. & Sankyo America, Inc. \\
\hline Hitachi Cable Indiana, Inc. & Seradyn, Inc. \\
\hline ICT Corporation & Seymour Tubing, Inc. \\
\hline Indiana Bolt and Nut Company & Sintering Technologies, Inc. \\
\hline Indiana Metal Coatings, Inc. & SMC Pneumatics, Inc. \\
\hline Indiana Packers Corporation & Subaru-Isuzu Automotive Inc. \\
\hline Indiana Precision Technology & Toyoshima Special Steel USA \\
\hline Intat Precision, Inc. & Toyota Industrial Equipment MFG., Inc. \\
\hline I/N Tek \& I/N Kote & Toyota Tsusho America, Inc. \\
\hline Jaytec, Inc. & \\
\hline
\end{tabular}


TABLE 2

Descriptive Statistics, Reliabilities, and Correlations for the Matched Sample ${ }^{\mathrm{a}}$

\begin{tabular}{|c|c|c|c|c|c|c|c|c|c|c|}
\hline Variables & Mean & $\underline{\mathrm{SD}}$ & $\underline{1}$ & $\underline{2}$ & $\underline{3}$ & $\underline{4}$ & $\underline{5}$ & $\underline{6}$ & $\underline{7}$ & $\underline{8}$ \\
\hline 1. Language proficiency & $\overline{3.20}$ & $\overline{1.50}$ & $(. \overline{9} 7)$ & & & & & & & \\
\hline 2. Previous knowledge & 2.81 & 1.34 & $.61 * * *$ & $(.93)$ & & & & & & \\
\hline 3. Willingness to communicate & 4.72 & 1.49 & .13 & .14 & $(.90)$ & & & & & \\
\hline 4. Culture novelty & 4.19 & 1.23 & $-.18 *$ & $-.27 * * *$ & .01 & $(.78)$ & & & & \\
\hline 5. General adjustment & 5.08 & 0.88 & $.29 * * *$ & $.31 * * *$ & $.24 * *$ & -.13 & $(.84)$ & & & \\
\hline 6. Work adjustment & 4.89 & 0.90 & $.51 * * *$ & $.44^{* * *}$ & .01 & $-.27 * * *$ & $.36 * * *$ & $(.81)$ & & \\
\hline 7. Interactional adjustment & 4.39 & 1.05 & $.63 * * *$ & $.53 * * *$ & $.19 * *$ & $-.15^{*}$ & $.41^{* * *}$ & $.64 * * *$ & $(.87)$ & \\
\hline 8. Intent to return early & 2.98 & 1.74 & $-.22 * *$ & $-.23 * * *$ & -.08 & $-.15 *$ & $-.32 * * *$ & $-.46 * * *$ & $.40 * * *$ & (.81) \\
\hline
\end{tabular}

Note: ${ }^{a} \mathrm{n}=170$; unless noted, all the rating scale is on a 7-point Likert type scale with $1=$ strongly disagree to $7=$ strongly agree; Cronbach's alphas are in the parentheses

$* \mathrm{p}<.05 ; * * \mathrm{p}<.01 ; * * * \mathrm{p}<.001$ (two-tailed) 
FIGURE 1

Hypothesized Relationships and Rating Sources in the Proposed Model of the Role of Expatriate Adjustment

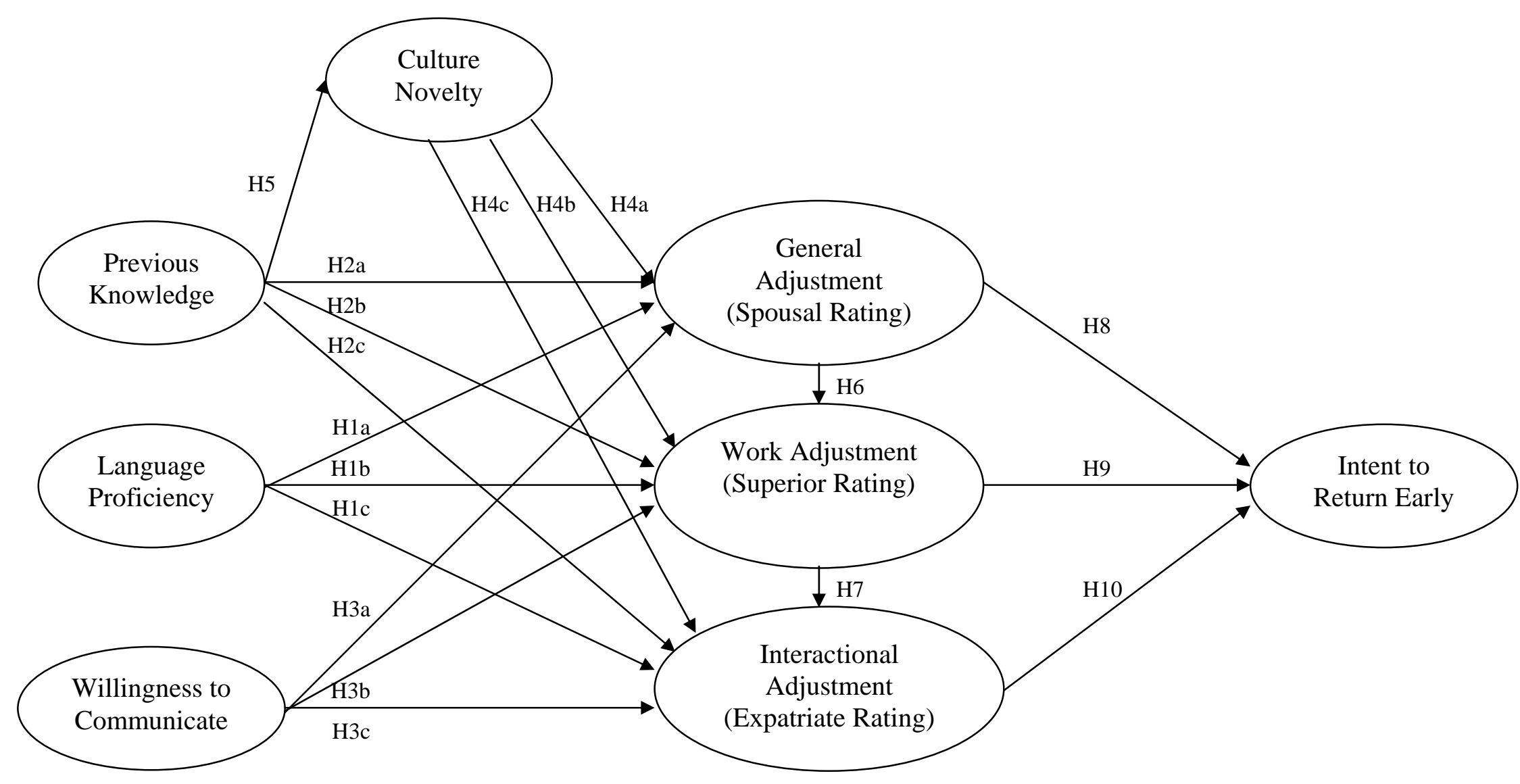




\section{FIGURE 2}

Results of the Intervening Model of Expatriate Adjustment

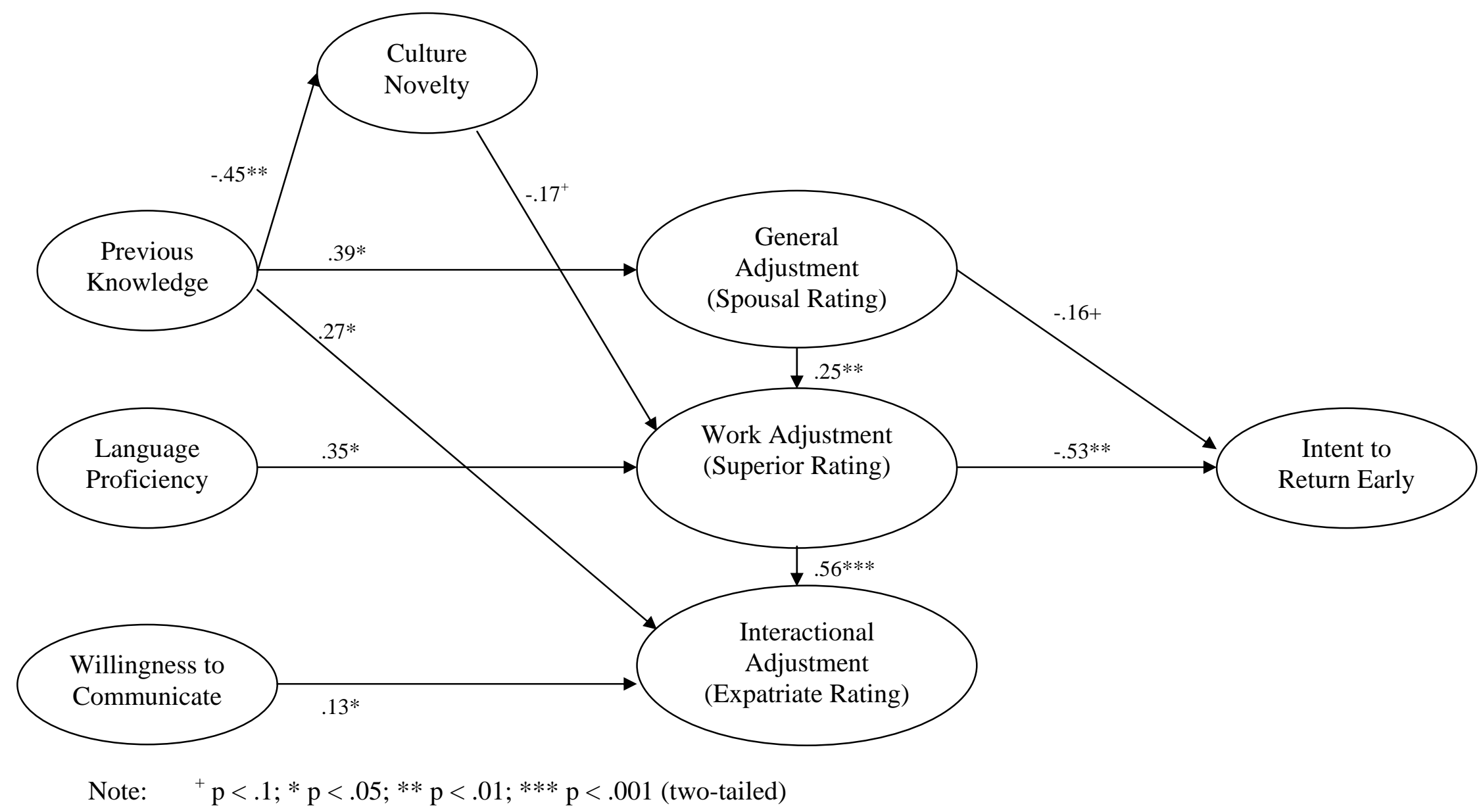


Appendix $\mathrm{A}^{\mathrm{a}}$

Confirmatory Factor Analysis

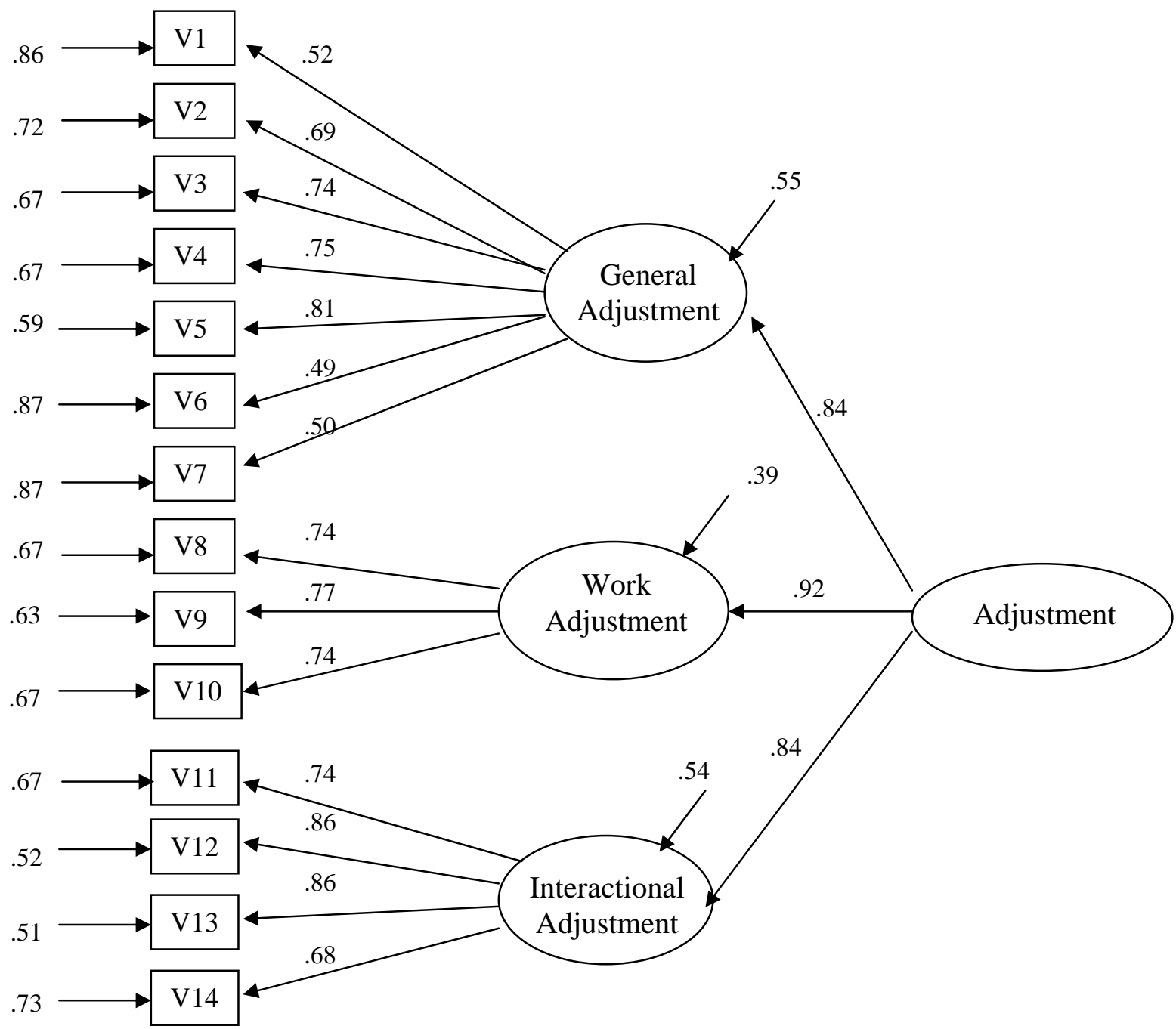

Note: All paths are significant at $\mathrm{p}<.001$. 